\title{
SÍNTESE DE NANOPARTÍCULAS DE PRATA COM ATIVIDADE ANTIMICROBIANA CONTRA Fusarium oxysporum: PROPOSTA DE AULA PRÁTICA PARA ALUNOS DE GRADUAÇÃO
}

\section{Gleys Kellen Aquino Moraes ${ }^{* 1}$, Luana Fernandes Ferraz ${ }^{1}$, Flávia Luane Gomes ${ }^{1}$, Lucas Samuel Soares dos Santos ${ }^{1}$}

${ }^{1}$ Universidade Federal do Tocantins, Campus Gurupi, Programa de Pós-Graduação em Biotecnologia, Gurupi-TO, Brasil.

*Correspondência: Universidade Federal do Tocantins, Gurupi, Tocantins, Brasil. CEP: 77404-970. e-mail: gleys_kellen@uft.edu.br.

\section{Artigo recebido em 14/03/2020 aprovado em 06/11/2020 publicado em 01/12/2020.}

\section{RESUMO}

A aplicação de aulas práticas contribui para a formação profissional dos alunos. O uso de nanopartículas de prata são uma alternativa viável de tratamento de microrganismos resistentes a antimicrobianos através da penetração na parede celular microbiana, o que leva a mudanças na permeabilidade celular e a morte. Objetiva-se sintetizar nanopartículas de prata e testar seu potencial antimicrobiano contra o fungo fitopatógeno Fusarium oxysporum. Foi preparada uma solução de nitrato de prata $\left(\mathrm{AgNO}_{3}\right)$ à $1 \mathrm{mmol} \mathrm{L}^{-1}$ e uma solução de Citrato de sódio à $10 \mathrm{mmol} \mathrm{L}$. A solução de $\mathrm{AgNO}_{3}(100 \mathrm{~mL})$ foi aquecida em chapa aquecedora sob agitação até atingir a temperatura de $100^{\circ} \mathrm{C}$, e adicionou-se $3 \mathrm{~mL}$ de citrato de sódio. Nessa etapa, marcou-se no cronometro 2 e 4 min, e retirou-se 2 mL da solução aquecida nos dois tempos. Foram adicionados $100 \mu \mathrm{L}$ das soluções em placas de Petri com meio BDA e inoculado um disco de $6 \mathrm{~mm}$ de $F$. oxysporum em cada placa. Como controle o fungo foi inoculado sem a presença das soluções. Após incubação de 7 dias o diâmetro do fungo foi medido e submetido à análise de variância. Foi observada a inibição do patogéno pelas soluções testadas de nanopartículas de prata.

Palavras-chave: Síntese, inibição, alternativa.

\section{INTRODUÇÃO}

$\mathrm{O}$ ingresso de estudantes em ensino superior no Brasil tem-se elevado gradativamente nos últimos anos. Em 2018, cerca de 3,4 milhões de alunos ingressaram em cursos de graduação, havendo o crescimento de 6,8\% em relação a 2017 (MEC, 2018). Com a grande demanda, as universidades têm elevado a busca por docentes nas mais diversas áreas de ensino.

O processo de aprendizagem dar-se por meio da captação das informações transmitidas pelo professor por meio de alguma didática, cabendo a este a responsabilidade sobre os conhecimentos do aluno em determinada área futuramente importante para sua atuação profissional (SANTO e LUZ, 2013).
A didática tradicional aborda a exposição do conteúdo por meio de aulas teóricas, memorização do conteúdo ministrado por parte dos alunos seguido de uma avaliação de aprendizagem, sendo bastante adotada por professores universitários que tendem a reproduzir a mesma metodologia de ensino na qual foram submetidos durante sua formação acadêmica (FREIRE, 2007; GIL, 2008).

O uso da experimentação como didática de ensino em química possibilita a criação de problemas reais estimulando o questionamento e a contextualização dos alunos (GUIMARÃES, 2009). Desta forma, a aplicação de aulas experimentais em cursos de graduação contribui para a formação 
profissional do aluno, em especial em cursos de exatas e engenharias, onde os alunos apresentam uma grande dificuldade em assimilar os conteúdos abordados.

O Brasil tem investido em nanotecnologia nos últimos anos e incentivado estudos nesta área por meio do Conselho Nacional de Desenvolvimento Científico e Tecnológico (CNPq) e Ministério de Ciência e Tecnologia (MCT), além disto, a nanotecnologia tem potencial para atender os objetivos do Milênio das Organizações das Nações Unidas (ONU) e também exerce grande influência econômica, tendo alcançado o consumo global em nanomateriais de US\$20,5 bilhões em 2010 (ABDI, 2010; SOUSA et al,2018).

Desta forma, a abordagem da nanociência em cursos graduação em química, biotecnologia e áreas afins, é extremamente importante, seja por meio de aulas teóricas ou por meio de experimentos. Neste artigo foram realizados experimentos didáticos para contextualizar conceitos químicos e biológicos como teorias de ligação metálica, reações de oxidaçãoredução, espectroscopia e efeito de ressonância de plasmons de superfície (MELO JR et al, 2012), além dos conhecimentos em microbiologia como cultivo de microrganismos e técnicas de repicagem microbiana.

O fungo Fusarium oxysporum é um fitopatógeno oportunista responsável por infectar cultivares de grande importância econômica, como o feijão (VIEIRA et al., 2016), milho (CAO et al., 2014) e banana (MICHIELSE, 2009), causando grandes prejuízos as lavouras. O gênero Fusarium também é responsável pela fusariose, doença capaz de afetar cultivares como a do abacaxi (NOGUEIRA et al., 2014), e apesar de raro, também pode acometer pacientes imunocompetentes (PINCELLI et al., 2008), provocando alta taxa de mortalidade.

Existe uma crescente busca de novos agentes antimicrobianos, com isso, as nanopartículas de prata são uma alternativa, visto que diversos estudos evidenciam sua eficiência antimicrobiana (FREIRE et al., 2018; GUZMAN et al., 2012). Estudos relataram que as nanopartículas de prata foram capazes de inibir fitopatógenos de gramíneas, pepino, arroz (KRISHNARAJ et al., 2012) e cacau (VILLAMIZARGALLARDO et al., 2016).

As nanopartículas atuam penetrando a parede celular microbiana, o que gera mudanças na permeabilidade da célula e consequentemente sua morte (SONDI, 2004). Outra forma de interação é através da liberação de íons de prata. Os íons liberados pelas nanopartículas irão interagir com as enzimas vitais da célula, como a NADH-desidrogenase II, inativando-a e liberando espécies reativas de oxigênio (DEEPAK E KALISHWARALAL, 2011), ocasionando a morte celular.

As nanopartículas de prata vêm se tornado atrativas do ponto de vista econômico por possuírem características como: baixa volatilidade, alta estabilidade e atividade antimicrobiana (VILLAMIZAR-GALLARDO et al, 2016), o que propicia seu uso em áreas como a agricultura e no controle antimicrobiano.

\section{MATERIAIS E MÉTODOS}

O presente trabalho foi desenvolvido por alunas do Programa de mestrado em Biotecnologia na disciplina de Nanomateriais. O experimento proposto foi conduzido com os demais alunos dessa mesma turma, envolvendo alunos dos programas de mestrado em Biotecnologia e Química da Universidade Federal do Tocantins, Campus Gurupi, nos laboratórios de Química e Microbiologia.

Trata-se de um experimento que pode ser aplicado em turmas em nível de graduação.

A turma foi dividida em dois grupos, nomeados como A e B, inicialmente foi realizada uma apresentação sobre o tema, demonstrando a importância do estudo em questão, da esterilização e limpeza dos utensílios a serem utilizados na prática. 
Os procedimentos foram divididos em três partes sendo preparo das soluções, síntese de nanopartículas de prata e estudo da atividade antimicrobiana.

\section{1ªrte: Preparo das soluções}

Antes do seu uso as vidrarias foram cuidadosamente lavadas (erlenmeyer, a tubos de ensaio, pipeta de vidro, béquer, proveta, bailarina) com água régia e água destilada. É importante que os alunos sejam alertados sobre a importância dessa etapa. A limpeza inadequada da vidraria prejudica a formação das nanopartículas e impossibilita o experimento. As impurezas presentes podem contaminar a solução e promover agregração das nanopartículas.

Em um balão volumétrico, foi preparada uma solução de nitrato de prata $\left(\mathrm{AgNO}_{3}\right) 1 \mathrm{mmol} \mathrm{L}^{-1} \mathrm{e}$ adicionouse, com auxílio de uma proveta $100 \mathrm{~mL}$, esta solução foi colocada em um erlemeyer de $250 \mathrm{~mL}$.

Preparou-se $50 \mathrm{~mL}$ de uma solução de citrato de sódio a $10 \mathrm{mmol} \mathrm{L}^{-1}$ que foi colocada em um béquer.

\section{$2^{\mathrm{a}}$ Parte: síntese das nanopartículas de prata}

Aqueceu-se $100 \mathrm{~mL}$ da solução de $\mathrm{AgNO}_{3}$ em uma chapa aquecedora sob agitação até atingir a temperatura de $100^{\circ} \mathrm{C}$. Em seguida, adicionou-se $3 \mathrm{~mL}$ de citrato de sódio, lentamente e com auxílio de uma pipeta de plástico. Alíquotas de $2 \mathrm{~mL}$ da mistura reacional foram retiradas em intervalos de tempo contados a partir do término da adição da solução de citrato. Cada grupo realizou sua retirada em tempos diferentes.

As amostras foram então analisadas num espectrofotômetro PG Instruments T-70 e depois utilizadas nos estudos de atividade antimicrobiana.

\section{$3^{\text {a }}$ Parte: Atividade Antimicrobiana}

Preparou-se asplacas de Petri com meio BDA (200 g batata, $20 \mathrm{~g}$ dextrose, $20 \mathrm{~g}$ ágar e $1 \mathrm{~L}$ de água destilada).
A cepa de $F$. oxysporum será inoculada em placas de Petri com meio BDA e incubada por 7 dias à $25^{\circ} \mathrm{C}$. As ponteiras e alças de drigalski foram autoclavadas. A câmara de fluxo laminar foi limpa com álcool 70 e o fluxo esterilizado com luz UV por $15 \mathrm{~min}$.

Inoculou-se $100 \mu \mathrm{L}$ da solução de 2 min em placas de Petri e espalhou-se com auxílio da alça de drigalski, em seguida inoculou-se um disco de $6 \mathrm{~mm}$ de $F$. oxysporum. As placas foram vedadas com parafilm e incubadas por 7 dias à $25^{\circ} \mathrm{C}$. Realizou-se o mesmo procedimento para todas as soluções de prata e para solução de $\mathrm{AgNO}_{3}$. Como controle inoculou-se um disco de $6 \mathrm{~mm}$ de $F$. oxysporum sem as soluções.

Após 7 dias o crescimento do fungo $F$. oxysporum foi medido com o auxílio de paquímetro em todas as placas. Os valores obtidos foram submetidos à análise de variância utilizando programa estatístico e a comparação das médias foi realizada pelo teste de Tukey.

\section{RESULTADOS E DISCUSSÃO}

Como descrito, a metodologia acima foi testada durante uma aula prática no curso de PósGraduação em Biotecnologia e Química, da UFT. Os alunos foram divididos em dois grupos, A e B.

Foi possível a obtenção de soluções de nanopartículas de prata estáveis com coloração amarela, de tonalidade clara a escura, de acordo com o do tempo de reação, como pode ser visto na Figura 1. Em 3 e 5 min obtêm-se uma solução de cor amarelo claro, e com 4 e 8 min uma solução de cor alaranjado escuro. A tonalidade amarela é resultado da absorção da radiação eletromagnética em ressonância com os plasmons de superfície. A estabilidade do sistema deriva do fato de que as nanopartículas formadas permanecem em suspensão sem se agregar e formar partículas maiores (MELO JR et al., 2012).

Os espectros de UV-Vis permitem uma avaliação mais da banda de ressonância da plasmons 
de superfície (SANTOS et al, 2020). Permitindo discussões a respeito do tamanho das partículas. Os espectros das soluções de nanopartículas são apresentados na Figura 2.

O grupo A obteve espectro das soluções nos tempos de 2, 6, 8 e 12 minutos. O comprimento de onda de máxima absorção (nm) para a solução amarelo claro (4 min) foi de $415 \mathrm{~nm}$, e a solução amarelo escuro ( $8 \mathrm{~min}$ ) foi de $426 \mathrm{~nm}$. Tal comportamento indica um aumento do tamanho das nanopartículas. Comportamento similar foi observado nos espectros do grupo B (Figura 3). A literatura (MELO JR et al., 2012) descreve que as nanopartículas de prata que apresentam cor amarela possuem diâmetro abaixo de $100 \mathrm{~nm}$.

Figura 1. Imagem das soluções obtidas pelos grupos em diferentes tempos de reação.

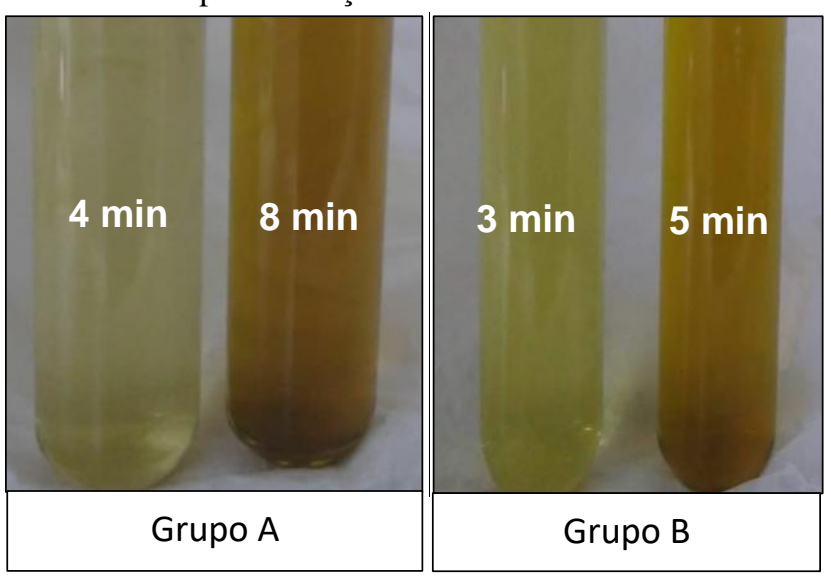

Figura 2. Espectro UV-VIS das nanopartículas de prata Grupo A.

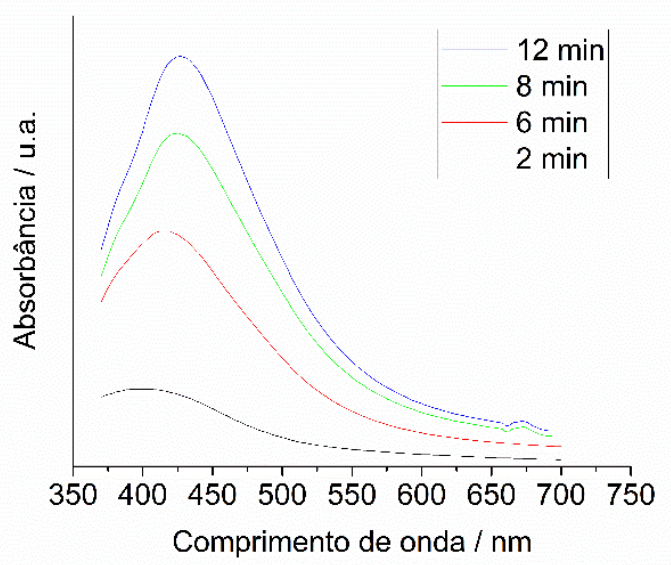

Figura 3. Espectro UV-VIS das nanopartículas de prata GrupoB.

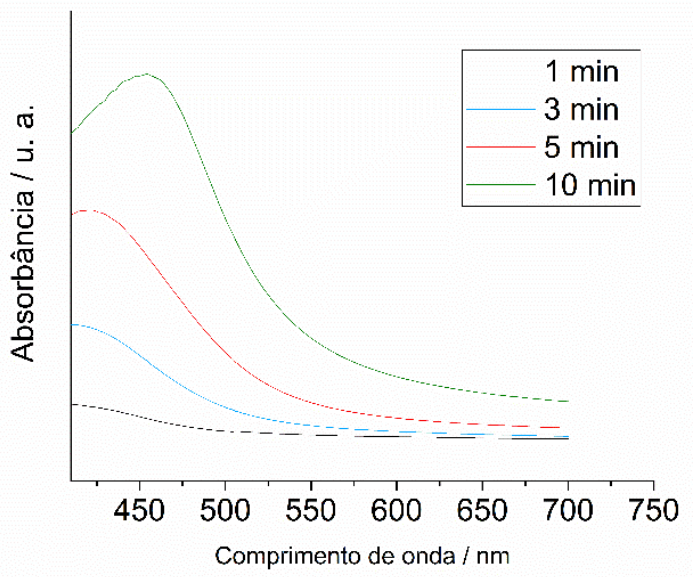

Quando a reação foi continuada por tempo superior a 15 minutos, observou-se a formação de uma solução turva e cinza, indicando que as partículas cresceram acima das dimensões manométricas.

$\mathrm{O}$ ensaio de atividade antimicrobiana evidenciou $o$ potencial antimicrobiano das nanopartículas de prata sintetizadas por ambos os grupos em diferentes tempos de reação e constatou-se a inibição de Fusarium oxysporum pelas soluções de nanopartículas de prata e $\mathrm{AgNO}_{3}$ quando comparados com a testemunha (Tabela 1). O tratamento T3 realizado pelo grupo A demonstrou a maior inibição de crescimento de $F$. oxysporum (Tabela 1), enquanto o tratamento T2 realizado pelo grupo B apontou a melhor inibição (Tabela 2).

O potencial promissor das nanopartículas de prata como antimicrobiano é visível quando comparamos o tratamento que teve o pior desenvolvimento com o controle. Mesmos os tratamentos $\mathrm{T} 2$ e $\mathrm{T} 1$ (grupos A e B, respectivamente) foram capazes de inibir o controle em 12, $8 \%$ e 9,3\%.

A atividade antimicrobiana desencadeada por nanopartículas de prata foi relatada em cepas de Candida albicans, Staphylococcus aureus (KISCHKEL et al., 2018), Enterococcus faecalis (PINTO, 2013), Salmonella typhymurium, 
Escherichia coli, Aspergillus niger e Trichophytum rubrum (PRADO, 2014).

Tabela 1. Médias da atividade antimicrobiana realizada pelo grupo A.

\begin{tabular}{cc}
\hline Tratamentos & Diâmetro de crescimento $\mathbf{( m m}$ ) \\
\hline $\mathrm{T} 1$ (4 minutos) & 48,2 \\
$\mathrm{~T} 2$ (8 minutos) & 58,2 \\
$\mathrm{~T} 3$ (turvo) & 28,7 \\
$\mathrm{AgNO}_{3}$ & 58,7 \\
Controle & 66,7 \\
\hline $\mathrm{CV}^{2}$ & 0
\end{tabular}

${ }^{1}$ Médias acompanhadas por mesma letra minúscula não diferem entre si pelo teste de Tukey a 5\% de significância. ${ }^{2}$ Coeficiente de variação.

Tabela 2. Médias da atividade antimicrobiana realizada pelo grupo B.

\begin{tabular}{cc}
\hline Tratamentos & Diâmetro de crescimento \\
\hline T1 (3 minutos) & $58,2 \mathrm{~d}$ \\
$\mathrm{~T} 2$ (5 minutos) & $45,5 \mathrm{a}$ \\
$\mathrm{T} 3$ (turvo) & $47,7 \mathrm{~b}$ \\
$\mathrm{AgNO}_{3}$ & $55,5 \mathrm{C}$ \\
Controle & $64,2 \mathrm{e}$ \\
\hline
\end{tabular}

\begin{tabular}{ll}
\hline $\mathrm{CV}^{2}$ & 0 \\
\hline
\end{tabular}

${ }^{1}$ Médias acompanhadas por mesma letra minúscula não diferem entre si pelo teste de Tukey a 5\% de significância. ${ }^{2}$ Coeficiente de variação.

Os mecanismos de interação entre as nanopartículas de prata com os microrganismos não foram totalmente elucidados, mas acredita-se que nas bactérias, as nanopartículas interagem com a membrana celular das mesmas causando danos em sua estrutura e provocando a lise celular (SONDI, SALOPEK-SONDI, 2004; LOK et al., 2006). Em outro mecanismo, os íons de prata podem interagir com fosfato das moléculas do DNA e inativar sua replicação, além disto, os íons de prata também podem atuar sobre as proteínas contendo enxofre, inibindo funções enzimáticas respiratórias da célula (MATSUMURA et al., 2003).

\section{CONCLUSÃO}

A metodologia de ensino desenvolvida para aulas práticas de nanotecnologia possibilitou o contato dos alunos de pós-graduação com as nanopartículas aplicadas a microbiologia, sendo possível a obtenção de nanopartículas de prata estáveis com tonalidade amarela. Foi observada a inibição de $F$. oxysporum por todas as soluções testadas, com isso o potencial antimicrobiano de nanopartículas de prata é evidenciado, demonstrando a importância da nanotecnologia na educação.

\section{AGRADECIMENTO}

Os autores agradecem à CAPES e aos programas de pós-graduação em Biotecnologia e em Química da UFT.

Todos os autores declararam não haver qualquer potencial conflito de interesses referente a este artigo.

\section{REFERÊNCIAS}

CAO, A.; SANTIAGO, R.; RAMOS, A. J.; SOUTO, X. C.; AGUÍN, O.; MALVAR, R. A.; BUTRÓN, A. Critical environmental and genotypic factors for Fusarium verticillioides infection, fungal growth and fumonisin contamination in maize grown in northwestern Spain. International Journal of Food Microbiology, v. 177, p. 63-71, 2014.

DEEPAK, V.; KALISHWARALAL, K. An Insight into the Bacterial Biogenesis of Silver Nanoparticles, Industrial Production and Scaleup. Metal Nanoparticles in Microbiology, p. 17-36, 2011.

FREIRE, N. B.; PIRES, L. C. S. R.; OLIVEIRA, H. P.; COSTA, M. M. Atividade antimicrobiana e antibiofilme de nanopartículas de prata sobre isolados de Aeromonas spp. obtidos de organismos aquáticos. Pesq. Vet. Bras. Vol. 38, n. 2, p.244-249, 2018.

GUZMAN, M; DILLE J.; GODET, S. Synthesis and antibacterial activity of silver nanoparticles against gram-positive and gramnegative bacteria. 
Nanomedicine: Nanotechnology, Biology, and Medicine, v. 8, n. 1, p. 37-45, 2012.

KISCHKEL, B.; YAMANAKA, A. H. U.; DEPIERI, N. B.; NEGRI, B. Nanopartículas de prata biossintetizadas por Mikania glomerata Sprengel inibem o crescimento de Candida albicans e Staphylococcus aureus. Arquivos de Ciências da Saúde, v. 25, n. 3, p. 46-52, 2018.

KRISHNARAJ, C.; RAMACHANDRAN, R.; KALAICHELVAN, P. T. Optimization for rapid synthesis of silver nanoparticles and its effect on phytopathogenic fungi. Spectrochimica Acta Part A: Molecular and Biomolecular Spectroscopy, v.93, p.95-99, 2012.

LOK, C. N.; HO, C. M.; CHEN, R.; HE, Q. Y.; YU, W. Y.; SUN, H.; TAM, P. K.; CHIU, J. F.; CHE, C. M. Proteomic analysis of the mode of antibacterial action of silver nanoparticles. J Proteome Res, v.5, n.4, p:916-924, 2006.

MATSUMURA, Y.; YOSHIKATA, K.; KUNISAKI, S.; TSUCHIDO, T. Mode of bactericidal action of silver zeolite and its comparison with that of silver nitrate. Appl Environ Microbiol. v.69, n.7, p: 427842812003.

MELO JR, M. A.; SANTOS, L. S. S.; GONÇALVES, M. C.; NOGUEIRA, A. F. Preparação de nanopartículas de prata e ouro: um método simples para a introdução da nanociência em laboratório de ensino. Quim. Nova, Vol. 35, No. 9, p. 1872-1878, 2012.

MICHIELSE, C. B. Pathogen profile update: Fusarium oxysporum. Molecular Plant Pathology, v. 10, p. 311-324, 2009.

NOGUEIRA, S. R.; LIMA, F. S.; ROCHA, E. M.; ARAÚJO, D. H. Fungicidas no controle de fusariose do abacaxi no estado de Tocantins, Brasil. Revista de Ciências Agrárias, v. 37, n.4, p. 447-455, 2014.

PINCELLI, T. P. H.; BRANDT, H. R. C.; MOTTA, A. L.; MACIEL, F. V. R.; CRIADO, P. R. Fusariose em paciente imunocomprometido: sucesso terapêutico com voriconazol Fusariosis in an immunocompromised patient: therapeutic success with voriconazole. An Bras Dermatol, v. 83, n. 4, p. 331-334, 2008.

PINTO, C. A. Avaliação do efeito antimicrobiano sobre Enterococcus faecalis e sua aderência promovido pelo cimento MTA com ou sem nanopartículas de prata. Tese (doutorado) Universidade de Taubaté, Departamento de Pósgraduação em Odontologia, 2013, 112 f.
PRADO, J. C. S. Nanopartículas de Prata: Biossíntese, Investigação das Atividades Antibacteriana, Antifúngica e Citotoxicidade. Dissertação (mestrado) - Universidade Estadual de Campinas, Faculdade de Ciências Aplicadas, 2014, 90 f.

SONDI, I. Silver nanoparticles as antimicrobial agent: A case study on E. coli as a model for Gramnegative bacteria. Journal of Colloid and Interface Science, v. 275, n. 1, p. 177-182, 2004.

SALOPEK-SONDI, B; SONDI, I. Silver nanoparticles as antimicrobial agent: a case study on E. coli as a model for Gram-negative bacteria. J Colloid Interface Sci. v.275, n.1, p.177-182, 2004.

VIEIRA, B. S.; VIEIRA, B. S.; SOUSA, L. A.; MENDONÇA, K. D. R. Potencial antagonístico de Bacillus subtilis (bsv-05) contra os patógenos radiculares do feijoeiro: Fusarium spp., Macrophomina phaseolina e Rhizoctonia solani. Ciência Agrícola, v. 14, n. 1, p. 59-66, 2016.

VILLAMIZAR-GALLARDO, R.; CRUZ, J. F. O.; ORTÍZ-RODRIGUEZ, O. O. O. Fungicidal effect of silver nanoparticles on toxigenic fungi in cocoa. Pesquisa Agropecuária Brasileira, Brasília, v.51, n.12, p.1929-1936, 2016.

MEC. Portal do Ministério da Educação. Censo da educação superior 2018. Disponível em: http://download.inep.gov.br/educacao_superior/censo _superior/documentos/2019/censo_da_educacao_sup erior_2018-notas_estatisticas.pdf. Acesso em 03 de março de 2020.

ABDI - Agência Brasileira de Desenvolvimento Industrial, "Cartilha Sobre Nanotecnologia", Cartilha Sobre Nanotecnologia, 2010, 60 pp.

FREIRE, Paulo. Pedagogia da autonomia: saberes necessários à prática educativa. $36^{\mathrm{a}}$ ed. São Paulo: Paz e Terra, 2007.GIL, Antonio Carlos. Didática do ensino superior. São Paulo: Atlas, 2008.

SANTO, E. E.; LUZ, L. C. S. Didática no ensino superior: Perspectivas e Desafios. SABERES, Natal RN, v. 1, n.8, ago. 2013, p.58-73.

GUIMARÃES, Cleidson, Carneiro. Experimentação no Ensino de Química: Caminhos e Descaminhos Rumo à Aprendizagem Significativa. QUÍMICA NOVA NA ESCOLA, Vol. 31, N 3, 2009.

SOUSA, C. R. S.; HOLANDA, A. D.; NUNES, A. B. A.; ALVES, G. S. A.; SAMPAIO, M. C. Nanotecnologia e nanociência: Considerações histórica e interdisciplinar, n. 25, p. 150-178, 2018.

SANTOS, L. S. S.; BARROS, S. B. A. ; RAHIM, ABDUR ; GUSHIKEM, Y. . In situ synthesis of gold 
nanoparticles on mesoporous silica surfacefunctionalized with pyridinium ligands. JOURNAL OF NANOPARTICLE RESEARCH , v. 22, p. 49, 2020. 